\title{
A Sociocultural Perspective on Knowledge Transfer in Mergers and Acquisitions
}

By: Riikka M. Sarala, Paulina Junni, Cary L. Cooper, and Shlomo Yedidia Tarba

Sarala, R.M., Junni, P., Cooper, \& Tarba, S. (2016). A Sociocultural Perspective on Knowledge Transfer in Mergers and Acquisitions. Journal of Management, 42(5), 1230-1249.

Made available courtesy of SAGE Publications: https://doi.org/10.1177/0149206314530167

****@ The Authors. Reprinted with permission. No further reproduction is authorized without written permission from SAGE. This version of the document is not the version of record. Figures and/or pictures may be missing from this format of the document. $* * *$

\begin{abstract}
:
Sociocultural factors are important determinants of merger and acquisition (M\&A) outcomes. Despite advances in this field, our understanding of sociocultural factors in M\&As remains incomplete. In particular, the roles of sociocultural interfirm linkages, HR flexibility, and organizational cultural differences in M\&As require further elucidation. The present article contributes to the M\&A literature by further clarifying the multifaceted role of these sociocultural factors in M\&As. We suggest that sociocultural interfirm linkages (complementary employee skills, trust, collective teaching, and cultural integration) between the merging firms influence the level of knowledge transfer in M\&As. Furthermore, we argue that HR flexibility (flexibility in employee skills, flexibility in employee behavior, and flexibility in HR practices) is vital for the development of the above-mentioned sociocultural interfirm linkages in M\&As. Finally, we maintain that organizational cultural differences are important antecedents of HR flexibility in M\&As.
\end{abstract}

Keywords: mergers | acquisitions | M\&A | knowledge transfer | culture | cultural differences | interfirm linkages | HR flexibility | strategic HRM

\section{Article:}

Mergers and acquisitions (M\&As) are important mechanisms for the growth and internationalization of firms. Previous studies have emphasized strategic fit and financial factors in M\&As, but have failed to provide consistent explanations for M\&A outcomes (Haleblian, Devers, McNamara, Carpenter, \& Davison, 2009; King, Dalton, Daily, \& Covin, 2004; Weber \& Fried, 2011). Recent studies have called for increased emphasis on examining the role of sociocultural factors in M\&As (Stahl et al., 2013; Weber \& Fried, 2011). This growing field of study focuses on the sociocultural issues involved in the integration of the merging firms (Cartwright \& Schoenberg, 2006; Stahl et al., 2013). Important topics in sociocultural M\&A studies include interfirm linkages (Birkinshaw, Bresman, \& Håkanson, 2000; Björkman, Stahl, \& Vaara, 2007), human resources (HR) (Aguilera \& Dencker, 2004; Schuler \& Jackson, 2001), and culture (Stahl \& Voigt, 2008; Teerikangas \& Very, 2006). Together, these studies show that sociocultural factors are important determinants of M\&A outcomes (Stahl et al., 2013). Despite advances in sociocultural M\&A studies, the field has been criticized for being atheoretical and 
fragmented (Seo \& Hill, 2005; Weber, 2012; Weber \& Fried, 2011). Several important research gaps remain. The aim of this conceptual article is to create a model that clarifies the multifaceted role of sociocultural factors in M\&As.

First, the role of interfirm linkages in M\&As has been underexplored, particularly regarding the sociocultural aspects of these linkages (Weber \& Fried, 2011; Zander \& Zander, 2010), and prior discussions have often been fragmented and lacking in theoretical grounding (Seo \& Hill, 2005). Nevertheless, interfirm linkages, that is, interfirm resources and routines, can be important sources of interorganizational competitive advantage (Dyer \& Singh, 1998). These linkages include complementary resource endowments, relation-specific assets, knowledge-sharing routines, and effective governance of the relationship (Dyer \& Singh, 1998). Applying this framework of interfirm linkages to M\&As, we identify important but underexplored sociocultural linkages: Complementary employee skills represent important complementary resource endowments, trust is a critical relation-specific asset, collective teaching is an essential knowledge-sharing routine, and cultural integration represents the sociocultural side of effective M\&A governance. Focusing on the effect of these sociocultural interfirm linkages on knowledge transfer in M\&As, we argue that they contribute to the ability of the merging firms to transfer knowledge. Knowledge transfer - successful transmission of knowledge (Davenport \& Prusak, 1998) between the acquiring and target firms - constitutes an important source of competitive advantage, and it contributes to M\&A performance (Björkman et al., 2007; Bresman, Birkinshaw, \& Nobel, 1999; Capron, 1999). It has been argued that the transfer of tacit and socially complex knowledge is a particularly important source of competitive advantage, and therefore constitutes an important goal in many M\&As (Björkman et al., 2007; Chaudhuri, 2005; Ranft, 2006; Ranft \& Lord, 2002). Knowledge transfer in M\&As, however, particularly the transfer of tacit and socially complex knowledge, is challenging because the unique, transitional, and hybrid organizational context during the integration process heightens the sociocultural barriers to knowledge transfer (Empson, 2001; Ranft \& Lord, 2002).

Second, although HR issues are critical in M\&As, they remain neglected in the M\&A literature (Schuler \& Jackson, 2001). Furthermore, much of the existing literature on the human side of M\&As has not been strongly grounded in theory (Seo \& Hill, 2005). As a result, important advances in the broader strategic HR management literature have not been integrated with the sociocultural M\&A literature. Specifically, the concept of HR flexibility (Way et al., 2015; Wright \& Snell, 1998) has not been applied to M\&As, although it seems especially relevant to this context. It has been argued that HR flexibility plays a particularly important role in contexts characterized by a high level of environmental and organizational change (Bhattacharya, Gibson, \& Doty, 2005; Milliman, von Glinow, \& Nathan, 1991). M\&As are often conducted as a direct response to changes in the dynamic competitive environment of a firm (Haspeslagh \& Jemison, 1991) and involve a high level of organizational change (Seo \& Hill, 2005). M\&As also have unique characteristics that make the role of HR flexibility in M\&As pertinent in this context. M\&As are more complex and challenging than other forms of organizational change because of the need to integrate the merging firms to create value (Haspeslagh \& Jemison, 1991; Schweizer, 2005). ${ }^{1}$ As a result, M\&As often involve sudden, drastic organizational changes under a high level of uncertainty and time pressure (Cartwright \& Cooper, 1996). Furthermore, M\&As bring together employees from two previously separate organizations with distinct organizational cultures, which can be challenging (Cartwright \& 
Cooper, 1996). Consequently, M\&As present a unique need to forge interfirm linkages that support the integration process, often in the context of considerable organizational cultural differences (Teerikangas \& Very, 2006). This adds complexity to the role of HR flexibility in M\&As compared with more traditional models on HR flexibility that tend to focus on intrafirm aspects. It is therefore particularly important to stress the role of HR flexibility in the unique context of M\&As.

To apply the conceptualization of HR flexibility to the M\&A context (Way et al., 2015; Wright \& Snell, 1998), we define HR flexibility as the capability of the merging firms to quickly adapt their HR to changing conditions during M\&A integration. HR flexibility consists of three components: flexibility in employee skills, flexibility in employee behavior, and flexibility in HR practices (Way et al., 2015; Wright \& Snell, 1998). Furthermore, each component contains the dimensions of resource and coordination flexibility (Way et al., 2015; Wright \& Snell, 1998). Applying this framework of HR flexibility (Way et al., 2015; Wright \& Snell, 1998) to the M\&A context, resource flexibility in employee skills reflects the extent to which employees of the merging firms have the ability to perform a broad range of alternative work activities during the M\&A integration process. Similarly, coordination flexibility in employee skills captures the capacity of the merging firms to quickly redeploy employees who have the ability to perform a broad range of alternative work activities to respond to the various needs arising during the integration process. Resource flexibility in employee behavior refers to the extent to which employees of the merging firms are willing to perform a broad range of alternative work activities during the integration process, whereas coordination flexibility in employee behavior in M\&As captures the ability of merging firms to deploy employees who are willing to apply a broad range of behavioral scripts to a wide variety of work activities that support the integration process. Finally, resource flexibility in HR practices refers to how easily the HR practices of the merging firms can be applied to a wide variety of employees in both firms working in different jobs in various contexts. In turn, coordination flexibility in HR practices reflects the capacity of the merging firms to quickly alter their HR practices to respond to the needs of dynamic M\&A integration. In this study, we argue that these components of HR flexibility play an important and previously undefined role in the formation of sociocultural interfirm linkages in M\&As.

Third, culture as a "higher-order" social structure in organizations is inherently connected to people and their management (Bowen \& Ostroff, 2004). Research on organizational cultural differences represents one of the most important topics in the sociocultural M\&A literature (Stahl \& Voigt, 2008). Researchers have argued that organizational cultural fit is as important as strategic fit in M\&As, if not more so (Cartwright \& Cooper, 1993). Nevertheless, the role of organizational cultural differences remains one of the "unresolved questions" in M\&A studies (Stahl et al., 2013; Stahl \& Voigt, 2008). Prior studies have provided mixed results on the effect of organizational cultural differences on M\&A outcomes (e.g., Vaara, Sarala, Stahl, \& Björkman, 2012; Westphal \& Shaw, 2005). One reason for these results is that many studies treat the integration process as a "black box," without making an adequate distinction between the mechanisms through which cultural differences affect M\&A outcomes (Stahl \& Voigt, 2008). To solve this puzzle, it is important to achieve a thorough understanding of how organizational cultural differences influence different aspects of HR during the integration process. To this end, we provide a fine-grained illustration of the effect of organizational cultural differences in M\&As by examining their impact on the components of HR flexibility. 
The present article contributes to the M\&A literature by further elaborating on the multifaceted role of sociocultural factors in M\&As. First, we apply the theory on interfirm relationships (Dyer \& Singh, 1998) to identify important sociocultural interfirm linkages that we ascertain to be important determinants of M\&A knowledge transfer. This contributes to the M\&A literature by clarifying the role of underresearched sociocultural linkages in M\&As. Second, we apply the concept of HR flexibility (Wright \& Snell, 1998) to the M\&A context and elaborate on how HR flexibility contributes to the development of sociocultural interfirm linkages. This advances the M\&A literature by extending the conceptualizations of HR in M\&As and by elaborating on the value-creation mechanisms of HR in M\&As. Third, we suggest that the effect of organizational cultural differences is exercised primarily through their impact on the components of HR flexibility. This furthers understanding of the mechanisms through which organizational cultural differences influence M\&As.

The article is structured as follows. First, we discuss the sociocultural perspective on M\&As. Next, we build a model that elaborates on the role of key sociocultural factors (sociocultural interfirm linkages, HR flexibility, organizational cultural differences) in M\&As. We conclude by discussing the limitations of the model and reflecting on the implications of the suggested model for research and practice.

\section{The Sociocultural Perspective on M\&As}

Sociocultural M\&A studies have examined the development of social connections across merging firms (Birkinshaw et al., 2000; Bresman et al., 1999; Ranft \& Lord, 2002; Schweiger \& Goulet, 2005). Although these discussions have been rather eclectic, ranging from cultural integration (Birkinshaw et al., 2000; Sarala \& Vaara, 2010; Schweiger \& Goulet, 2005) to the creation of trust (Stahl, Larsson, Kremershof, \& Sitkin, 2011), they highlighted the importance of establishing sociocultural interfirm linkages between the merging firms as determinants of M\&A outcomes. Although establishing these kinds of sociocultural linkages is described as one of the most challenging aspects of M\&As (Evans \& Pucik, 2005), they are essential for supporting the building of strategic and operational links between the firms. Despite growing interest in this area, several topics within this stream of literature remain underresearched and often lack theoretical grounding (Seo \& Hill, 2005; Weber \& Fried, 2011), resulting in a lack of comprehensive understanding of the contribution of sociocultural linkages to M\&A outcomes. To illustrate the main categories of interfirm links in M\&As, we use the interfirm linkages framework of Dyer and Singh (1998)as the theoretical foundation of our model. We highlight particularly important but underexplored sociocultural factors within each category.

In the area of HR, the sociocultural literature on M\&As focuses primarily on understanding employees' psychological and behavioral reactions to an acquisition. M\&As increase negative reactions such as anxiety (Ivancevich, Schweiger, \& Power, 1987), ambiguity (Risberg, 2001; Vaara, 2003), and lack of organizational commitment (Cartwright \& Cooper, 1996). These reactions are explained by the material (e.g., job insecurity) and identity threats posed by M\&As (van Dick, Ullrich, \& Tissington, 2006). The sociocultural M\&A literature has also argued that HR practices play a crucial role in M\&As (Schweiger \& Lippert, 2005). These practices should be vertically aligned with the acquisition strategy (Aguilera \& Dencker, 2004; Napier, 
1989; Rees \& Edwards, 2009) and the stage of the acquisition process (Hunt \& Downing, 1990; Ivancevich et al., 1987; Schuler \& Jackson, 2001). HR practices should also be horizontally aligned to reinforce each other and to avoid conflicts in the multiple roles of the HR function (Björkman \& Søderberg, 2003). Nevertheless, recent M\&A studies have called for research to further elaborate on the role of HR in M\&As (Weber \& Drori, 2011; Weber \& Fried, 2011). Specifically, recent advances in the broader HR management literature, involving increased focus on the capacity of HR to adapt to changing circumstances (i.e., HR flexibility), have great potential for explaining the role played by HR in M\&A integration. In our model, we apply the concept of HR flexibility to M\&As and examine its sociocultural determinants and outcomes.

Finally, research on organizational cultural differences in M\&As is an integral part of the sociocultural M\&A literature. M\&A researchers have argued that organizational cultural differences, that is, differences in shared assumptions, values, and norms between employees of the acquiring and target firms (Schein, 1996; Shrivastava, 1986), tend to stand in the way of M\&A value creation (Cartwright \& Cooper, 1993; Chatterjee, Lubatkin, Schweiger, \& Weber, 1992; Datta, 1991; Stahl \& Voigt, 2008). Consistent with this, many of the HR-related difficulties in M\&As have been attributed to problems arising from organizational cultural differences between the merging firms (Elsass \& Veiga, 1994; Lubatkin, Schweiger, \& Weber, 1999). Nevertheless, some M\&A studies have pointed out the possible positive effects of organizational cultural differences in M\&As (Björkman et al., 2007; Krishnan, Miller, \& Judge, 1997; Vaara et al., 2012; Vermeulen, 2005). Others have found mixed effects (Weber, Shenkar, $\&$ Raveh, 1996). We argue that these conflicting results are at least partly due to an incomplete conceptualization of the sociocultural mechanisms through which cultural differences influence M\&A outcomes (Teerikangas \& Very, 2006). Researchers have urged that future studies focus on how cultural differences interact with other variables affecting M\&A outcomes (Stahl, Mendenhall, \& Weber, 2005). We therefore elaborate on HR flexibility and interfirm linkages as mediators of the effect of organizational cultural differences in M\&As.

Our literature review reveals several important gaps in the sociocultural M\&A literature. Particularly, the role of sociocultural interfirm linkages in M\&As requires further theoretically grounded examination. Moreover, the role of HR flexibility has been neglected in the literature. Finally, studies on organizational cultural differences have provided mixed results, which may be due to the omission of important variables from these models. We proceed to address these research gaps in the following conceptual model.

\section{Proposition Development}

\section{Creation of Sociocultural Interfirm Linkages and M\&A Knowledge Transfer}

M\&As offer access to valuable, rare, difficult to imitate, and nonsubstitutable resources and resource combinations that contribute to value creation by the firm (Barney, 1991). The value of these resources, particularly of knowledge, can be realized through knowledge transfer. Knowledge transfer is defined as the successful transmission of knowledge, including the sending or presenting of knowledge to a potential recipient and the absorption of knowledge by the recipient (Davenport \& Prusak, 1998). Several prior studies have shown that knowledge 
transfer is critical in M\&As (Ahammad \& Glaister, 2011; Capron, 1999; Capron \& Pistre, 2002). M\&As can be seen as a means to broaden the knowledge base of the acquiring firm and to create new and innovative knowledge combinations based on the knowledge of the merged firms (Björkman et al., 2007; Vermeulen \& Barkema, 2001). However, knowledge that is the most likely to contribute to value creation is also likely to contain elements that are tacit, socially complex, and therefore challenging to transfer between the merging firms (Björkman et al., 2007; Chaudhuri, 2005; Ranft \& Lord, 2002). This type of knowledge cannot be transferred without developing a complex set of interfirm linkages between the merging firms and their employees. Based on the relational view (Dyer \& Singh, 1998), we understand these interfirm linkages to consist of complementary resource endowments, relation-specific assets, knowledgesharing routines, and effective governance. Consistent with the underlying sociocultural perspective of the present study, our focus is on important but underresearched sociocultural interfirm linkages.

First, complementary resource endowments are resources of both partners that, when combined, result in synergies (Dyer \& Singh, 1998). From a sociocultural perspective, complementary resource endowments in M\&As relate primarily to the extent of complementary skills among employees of the merging firms. Based on the general definition of complementary knowledge (Björkman et al., 2007; Jap, 1999), we define complementary employee skills as skills possessed by the employees of the acquiring and target firms that allow employees to pursue together goals that they could not accomplish on their own. Complementary employee skills contribute to knowledge transfer because they help fill existing gaps in the employees' skills. Complementary employee skills can therefore be seen as more valuable than overlapping or substitutable skills, and are more likely to be transferred between the merging firms (Westphal \& Shaw, 2005). For instance, when Cisco acquired Grand Junction, complementary employee skills at Cisco in local area network switching products and at Grand Junction in Ethernet desktop switching products contributed to knowledge transfer, which allowed the merging firms to create complete Internet solutions for small and medium-size enterprises (Chaudhuri, 2005).

Second, relation-specific assets of both partners are specific to a given relationship, created as the employees of the two firms work together (Dyer \& Singh, 1998). From a sociocultural perspective, we argue that one of the most important but underexamined relation-specific assets in M\&As is trust between the employees of the merging firms (Graebner, 2009; Stahl et al., 2011; Stahl et al., 2013; Stahl \& Sitkin, 2005). We conceptualize trust between the merging firms as the willingness of the employees to be vulnerable to the partner firm because they expect the partner firm to have positive intentions (Rousseau, Sitkin, Burt, \& Camerer, 1998; Stahl et al., 2011). We maintain that building trust between the merging firms is particularly important for knowledge transfer in M\&As (Birkinshaw et al., 2000) because it mitigates problems related to employee resistance, such as fear of exploitation and contamination (Empson, 2001; Junni, 2011). Moreover, trust facilitates the building of strong ties between members of the organization, which may be necessary particularly for the transfer of tacit and socially complex knowledge (Frantz, 2012).

Third, knowledge-sharing routines refer to the institutional interfirm processes put in place to support knowledge transfer (Dyer \& Singh, 1998). It has been argued that collective teaching is particularly useful in the transfer of tacit and socially complex knowledge (Zhao \& Anand, 
2009). We suggest that collective teaching is a particularly important but under-researched sociocultural knowledge-sharing routine in M\&As. Collective teaching refers to activities in which employees of one firm observe the employees of the other firm in the performance of their tasks (Zhao \& Anand, 2009). Direct observation allows the employees to learn about the tacit and socially complex aspects of the partner firm's knowledge, which are embedded in daily routines and interactions (Zhao \& Anand, 2013). Such knowledge is exposed by blending people across the merging firms. For example, when Cisco acquired Grand Junction, Grand Junction employees were paired up with "buddies" from Cisco who showed them how Cisco worked, while Cisco employees learned from observing their peers at Grand Junction (Chaudhuri, 2005).

Finally, effective governance refers to the control and coordination of the relationship between the firms and their employees (Dyer \& Singh, 1998). We understand organizational culture as a social control system that is based on shared assumptions, norms, and values (O'Reilly \& Chatman, 1996). Therefore, from a sociocultural perspective, effective governance in M\&As consists of social control through cultural integration of the merging firms (Birkinshaw et al., 2000). Cultural integration refers to aligning the assumptions, values, and norms of the merging firms through convergence (the firms become more similar along existing cultural dimensions) or through crossvergence (new cultural dimensions are created) (Sarala \& Vaara, 2010). This produces a shared social platform for knowledge transfer by making it easier for employees to understand the knowledge that resides in the partner firm and how it can be used (Junni \& Sarala, 2011; Sarala \& Vaara, 2010). For example, in the Nordea merger that combined four Nordic banks and involved significant knowledge transfer, cultural integration through the creation of a new "Nordic" identity and cultural values was considered essential (Vaara, Tienari, \& Björkman, 2003; Vaara, Tienari, \& Irrmann, 2007). In light of the above discussion we suggest the following:

Proposition 1: Sociocultural interfirm linkages, that is, complementary resource endowments, relation-specific assets, knowledge-sharing routines, and effective governance of the integration process, contribute to M\&A knowledge transfer.

Flexibility in Employee Skills and the Creation of Sociocultural Interfirm Linkages

Flexibility in employee skills and complementary resource endowments. We propose that both resource and coordination flexibility in employee skills contribute to complementary resource endowments through complementary employee skills. Resource flexibility in employee skills (Way et al., 2015; Wright \& Snell, 1998) reflects the extent to which employees of the merging firms can perform a broad range of alternative work activities during the M\&A integration process. The broader the range of alternative work activities that employees can perform, the greater the likelihood of complementarity in employee skills across the merging firms. Thus, broader employee skills are more likely to help fill "gaps" in the partners' knowledge bases and allow employees to pursue new goals and to accomplish new tasks together that they could not have done on their own. In contrast, if the resource flexibility in employee skills is low, the employees of the merging firms are able to perform only a narrow range of work activities, which reduces the likelihood that their skills are complementary. For instance, in Cisco's acquisition of Grand Junction, the employees of the two firms possessed resource flexibility in their skills, that is, they were able to perform together a broader range of work activities during 
the M\&A integration process than they would have been able to do on their own. Specifically, the Cisco and Grand Junction engineers applied their respective LAN switching skills in combination with Ethernet desktop switching skills. This allowed them to pursue new goals together and provide complete Internet solutions (Chaudhuri, 2005). Coordination flexibility in employee skills - the capacity of the merging firms to quickly redeploy across the firms employees who have the ability to perform a broad range of alternative work activities — allows the firms to identify employees with potentially complementary skills and quickly assign them to new roles so that they can start pursuing new goals together. Without coordination flexibility, resource flexibility in employee skills remains "unused potential" to accomplish new things together. For example, Quickturn's acquisition of SpeedSim was motivated by access to the simulation software skills of SpeedSim employees, which were to complement the emulation product skills of Quickturn employees (Zafar \& Chang, 2012). This would have allowed the firms to provide their customers with a full range of services in computer chip design, from early stages (using the SpeedSim software) to later stages (using the Quickturn products) (Zafar \& Chang, 2012). But the firms were not able to leverage the ability to accomplish this new goal together because Quickturn lacked coordination flexibility and was therefore unable to successfully identify and redeploy employees with complementary skills. We therefore propose the following:

Proposition 2: In M\&As, greater resource and coordination flexibility in employee skills contribute to complementary resource endowments.

Flexibility in Employee Behavior and the Creation of Sociocultural Interfirm Linkages

Flexibility in employee behavior and relation-specific assets. We propose that both resource and coordination flexibility in employee behavior support the creation of an important relationspecific asset - trust - in M\&As. Resource flexibility in employee behavior (Way et al., 2015; Wright \& Snell, 1998) refers to the extent to which employees of the merging firms are willing to perform a broad range of alternative tasks, and therefore determines how employees use their skills during M\&A integration. Employees with a high level of behavioral resource flexibility are willing to adopt different types of behaviors, depending on their appropriateness (Wright \& Snell, 1998). Resource flexibility in employee behavior also implies a higher tolerance for nonroutine behavior, so that employees are willing to adjust their behavioral responses to new circumstances based on improvisation rather than resort to fixed patterns of action (Beltran-Martin, Roca-Puig, Escrig-Tena, \& Bou-Llusar, 2008). This encourages employees to engage in new and nonroutine activities (Beltran-Martin et al., 2008) and makes them likely to collaborate with their partners in the integration process. Willingness to collaborate enables the creation of trust between the employees of the merging firms because trust is built over time as a result of cooperation with the partner firm (Stahl et al., 2011). In turn, coordination flexibility in employee behavior (Way et al., 2015) refers to the ability of the merging firms to deploy across the firms employees who have a wide variety of behavioral scripts and who are willing to apply these behaviors in a variety of work activities. This enables the merging firms to determine which employees have behavioral attributes that are suitable for key integration roles. For instance, the roles of integration manager (Teerikangas, Very, \& Pisano, 2011) and cross-organizational liaison are essential for building trust (Birkinshaw et al., 2000; Ranft \& Lord, 2002), but require merging firms to identify and deploy employees who can 
function effectively in these demanding roles that require great behavioral flexibility. Therefore, we suggest the following:

Proposition 3a: In M\&As, resource and coordination flexibility in employee behavior contribute to the creation of relation-specific assets.

Flexibility in employee behavior and knowledge-sharing routines. We propose that resource and coordination flexibility in employee behavior support the development of an important sociocultural knowledge-sharing routine, namely collective teaching. Resource flexibility in employee behavior supports collective teaching because the willingness of the employees of the merging firms to perform a broad range of alternative tasks increases the likelihood of active employee participation. Collective teaching is not possible without active employee participation (Zhao \& Anand, 2009) and willingness to engage in new activities. For example, creation of the "buddy system" used in the integration of Cisco and Grand Junction (Chaudhuri, 2005) required employees from both sides to take part in activities outside their regular work tasks. Collective teaching also requires coordination flexibility in employee behavior because the partner firms must be able to determine the desired employee behaviors in order to choose employees who can serve as "teachers," to select employees who are willing to learn from their partners, and to assign these employees to key "teaching" and "learning" roles. Hence, we propose the following:

Proposition 3b: In M\&As, resource and coordination flexibility in employee behavior facilitate the creation of knowledge-sharing routines.

Flexibility in employee behavior and effective governance. We suggest that resource and coordination flexibility in employee behavior facilitate the effective governance of M\&As by supporting cultural integration. Resource flexibility in employee behavior increases the willingness of employees to engage in new behaviors because employees are less fixated on preacquisition assumptions, values, and norms. For cultural integration to take place, employees must engage in new behaviors in order to verify the validity of the new culture and to explore how they can contribute to it (Kavanagh \& Ashkanasy, 2006). Furthermore, employees with high behavioral resource flexibility are more likely to participate in socialization activities that support cultural integration, such as cultural learning initiatives (Schweiger \& Goulet, 2005). Participation in social activities promotes commitment and is therefore an essential mechanism for social control (O'Reilly \& Chatman, 1996) through cultural integration. In addition, coordination flexibility in employee behavior supports cultural integration because it helps identify those individuals in the merging firms who are particularly willing to engage in new behaviors that are consistent with the desired culture. Identifying these employees and placing them in key node positions is important because these individuals are more likely to engage in positive discourses that mobilize their peers (Graebner, 2004) to create a new common culture. This may also mitigate "collective rumination" among employees, that is, the passive and repeated discussion with peers of organizational problems and their negative consequences (Marmenout, 2011), because these key persons are able to communicate the value of the new culture. Clear messages from valued coworkers, consistent with the desired culture, are essential for managing by social control (O’Reilly \& Chatman, 1996). Thus, we suggest the following: 
Proposition 3c: In M\&As, resource and coordination flexibility in employee behavior facilitate effective governance.

Flexibility in HR Practices and the Creation of Sociocultural Interfirm Linkages

Flexibility in HR practices and relation-specific assets. We propose that both resource and coordination flexibility in HR practices support the creation of an important relation-specific asset, trust, in M\&As. Resource flexibility in HR practices refers to how easily the HR practices of the merging firms can be applied in both firms to a wide variety of employees who work in different jobs in various contexts. Thus, high resource flexibility in HR practices implies that the practices are broad enough (Wright \& Snell, 1998) to be applied widely across the merging firms. When HR practices are aligned, the employees of both firms are treated more equally, which helps build trust between the employees in the merging firms over time (Stahl et al., 2011). In turn, coordination flexibility in HR practices reflects the capacity of the merging firms to quickly change their HR practices depending on integration needs. This is important because successful M\&A integration is ultimately an adaptive process in which initial plans often have to be adapted to unexpected events and discoveries (Gates \& Very, 2003). Merging firms with a high level of coordination flexibility in HR practices can quickly implement new configurations of HR practices in response to changing conditions. The firms can also receive fast feedback on the effectiveness of the practices from the point of view of the merger partner, so that HR practices that are not working can be reconfigured. Thus, coordination flexibility allows for increased responsiveness to the needs of the partner, which further facilitates the development of trust between the merging firms (Parkhe, 1993; Stahl et al., 2011). For example, in Daimler's acquisition of Chrysler, a lack of resource flexibility in HR practices (the HR practices of both firms were narrow and context-specific) and a lack of coordination flexibility in HR practices (the firms were incapable of quickly altering their HR practices) impeded the building of trust between the merging firms (Kühlmann \& Dowling, 2005). Hence, we propose the following:

Proposition 4a: In M\&As, resource and coordination flexibility in HR practices facilitate the creation of relation-specific assets.

Flexibility in HR practices and knowledge-sharing routines. We propose that both resource and coordination flexibility in HR practices play a key role in the creation of sociocultural knowledge-sharing routines, among which collective teaching is particularly important. Because resource flexibility in HR practices means that these can be applied broadly (Wright \& Snell, 1998) in the merging firms, it is easy to use general HR practices, such as broadly applicable training and mentoring programs, as a platform for collective teaching activities during M\&A integration. In turn, coordination flexibility in HR practices allows firms to quickly change their HR practices so that they better support collective teaching activities. For instance, reward systems can encourage employee participation in collective teaching by including it in performance evaluations (Lakshman, 2011). Thus, we suggest the following:

Proposition 4b: In M\&As, resource and coordination flexibility in HR practices facilitate the creation of knowledge-sharing routines. 
Flexibility in HR practices and effective governance. We propose that both resource and coordination flexibility in HR practices contribute to the effective governance of the acquisition process by facilitating cultural integration. Resource flexibility in HR practices supports cultural integration because broad practices are applicable to a multitude of contexts, including that of the partner firm. Thus, HR practices that have high resource flexibility can be applied broadly across the merging firms to support cultural changes. For instance, comprehensive use of reward systems that provide an incentive to comply with core norms and values is an important mechanism for social control (O'Reilly \& Chatman, 1996). Therefore, cultural integration is enhanced by the introduction of shared HR practices that are aligned with the new, desired culture. Coordination flexibility in HR practices allows the merging firms to try out new HR practices early in the integration process and to receive prompt feedback about their appropriateness in the cultural context of the partner firm. This allows the firms to further optimize HR practices. For example, when Ciba-Geigy and Sandoz combined to form Novartis, the merging firms demonstrated resource flexibility in HR practices by developing a broad performance appraisal system that could be applied worldwide. As a part of their performance appraisal, all Novartis managers were evaluated on eight shared "Novartis" values and related behaviors (Chua, Engeli, \& Stahl, 2005). This kind of performance appraisal system played an integral role in supporting the cultural integration that took place through the development of a new high-performance culture based on new "Novartis" values (Chua et al., 2005). Novartis also showed coordination flexibility in HR practices by taking quick corrective action based on the feedback received. As integration progressed, the performance appraisal system and other HR practices that were implemented to support the new culture were fine-tuned (Chua et al., 2005). Consequently, we propose the following:

Proposition 4c: In M\&As, resource and coordination flexibility in HR practices facilitate effective governance.

Organizational Cultural Differences and HR Flexibility

Organizational cultural differences and flexibility in employee skills. Organizational culture refers to the shared assumptions, values, and norms held by people belonging to the same organization (Schein, 1996; Shrivastava, 1986). Organizational culture represents a "higherorder" social structure in organizations (Bowen \& Ostroff, 2004); it affects the type of employee skills, behaviors, and HR practices that are valued in a firm, encouraging some and discouraging others (Barney, 1986; Schein, 1996). Hence, when the acquiring and target firms have sharply different organizational cultures, their employees are more likely to possess fundamentally different skills and behavior, and the HR practices of the firms are likely to be dissimilar.

We propose that dissimilarities in employee skills resulting from organizational cultural differences between the acquiring and the target firms increase resource flexibility in employee skills. The heterogeneity of employee skills that stems from cultural differences is likely to create a broader skill base between the acquiring and target firms because the employees are likely to possess different types of knowledge and engage in different kinds of work (Björkman et al., 2007; Vaara et al., 2012). Moreover, heterogeneous skills resulting from organizational cultural differences break existing rigidities and path dependencies in the employee skills of the acquiring and target firms (Marks \& Mirvis, 2011; Shreyögg, 2005) and provide strong inputs for 
creativity (Stahl, Maznevski, Voigt, \& Jonsen, 2010), which is likely to further broaden employee skills. Organizational cultural differences are therefore likely to increase resource flexibility in employee skills. In contrast, we expect organizational cultural differences to decrease coordination flexibility in employee skills. Organizational cultural differences make it more difficult to identify employees in the partner firm with the most critical skills (Björkman et al., 2007; Chaudhuri \& Tabrizi, 1999; Haspeslagh \& Jemison, 1991). Rapid identification and redeployment of skilled employees is therefore more difficult. This results in a decrease in the coordination flexibility of employee skills. Accordingly, we propose the following:

Proposition 5a: In M\&As, organizational cultural differences facilitate resource flexibility in employee skills, but hinder coordination flexibility in employee skills.

Organizational cultural differences and flexibility in employee behavior. We propose that organizational cultural differences have a negative effect on resource and coordination flexibility in employee behavior. Organizational cultural differences are likely to be associated with differences in employee behavior (Barney, 1986), making it more difficult to interpret the behavior of employees in the partner firm correctly (Chatterjee et al., 1992). The resulting misunderstandings and behavioral ambiguity increase the likelihood of negative social identification, so that employees in the partner firm will be considered an "outgroup" (Vaara, 2003). Negative social identification reduces the willingness of employees to engage in adaptive behavior (Cartwright \& Cooper, 1996; van Dick et al., 2006) and results in a decrease in resource flexibility in employee behavior. Furthermore, organizational cultural differences can reduce coordination flexibility in employee behavior by making it more difficult to determine how willing employees are to work on a project; this is because organizational cultural differences complicate the interpretation of employee behavior and increase the likelihood of misinterpretation (Evans, Pucik, \& Björkman, 2011; Weber, 1996). For instance, organizational cultures differ in relation to decision-making style (Evans et al., 2011). Employees of a target firm that uses consultative decision-making style may openly challenge and question integration decisions. If the culture of the acquiring firm is characterized by authority-based decision making, employees of such a target firm may be incorrectly labeled as "non-team players." Misunderstandings of this type, resulting from organizational cultural differences, make it challenging to interpret employee behavior effectively, resulting in decreased coordination flexibility in employee behavior. Hence, we suggest the following:

Proposition 5b: In M\&As, organizational cultural differences reduce resource and coordination flexibility in employee behavior.

Organizational cultural differences and flexibility in HR practices. Organizational cultural differences also influence resource and coordination flexibility in HR practices. Organizational cultural differences make it more difficult to create broad HR practices that are applicable to the unique organizational contexts of both firms. For example, introduction of a shared compensation system based on individual achievement is unlikely to work if one of the firms has a team-oriented culture (Evans et al., 2011). Or, if the merging firms have different assumptions about what drives business strategy, for example, one firm values tradition while the other encourages innovation (Evans et al., 2011), promotion by seniority is unlikely to work in the innovation-oriented firm. This reduces resource flexibility in HR practices by limiting the ability 
to create HR practices that would effectively apply to both firms. Concerning coordination flexibility in HR practices, it is difficult to quickly adapt new HR practices in merging firms with large differences in organizational culture because these differences need first to be understood (Evans et al., 2011). Making sense of organizational cultural differences can be a complex and time-consuming process that is vulnerable to prejudices and misinterpretations (Vaara, 2003; Weber, 1996; Weber \& Tarba, 2012). For instance, after Unilever acquired Ben \& Jerry’s, it took the time necessary to understand the latter's organizational culture before making any changes to the HR practices. The aim was to avoid damaging those aspects of the culture that contributed to Ben \& Jerry's competitive advantage (Austin \& Leonard, 2008). Hence, we propose the following:

Proposition 5c: In M\&As, organizational cultural differences hinder resource and coordination flexibility in HR practices.

The theoretical model is illustrated in Figure 1.

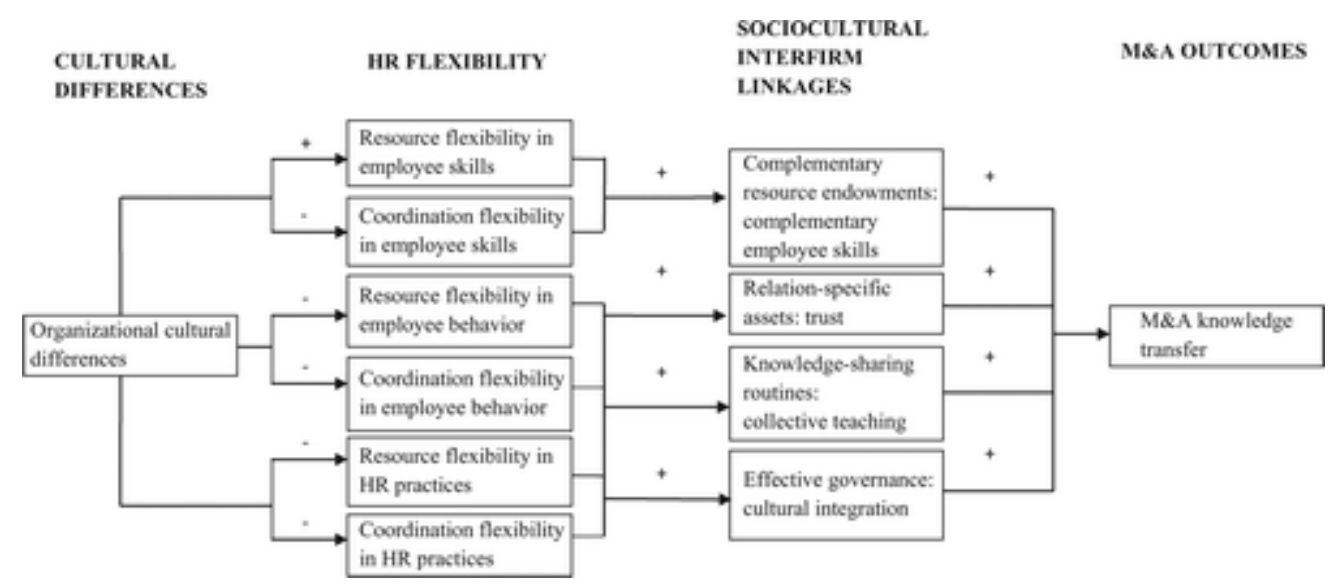

Figure 1. Theoretical Framework

\section{Discussion}

The aim of this conceptual article was to create a model that further clarifies the multifaceted role of sociocultural factors in M\&As. First, we applied the interfirm linkages framework (Dyer \& Singh, 1998) to M\&As in order to provide a theoretically grounded identification of important, underexplored sociocultural interfirm linkages in M\&As. These included complementary employee skills as an important type of complementary resource endowments, trust as a critical relation-specific asset, collective teaching as an important knowledge-sharing routine, and cultural integration as representing the sociocultural side of effective M\&A governance. We further proposed that these sociocultural interfirm linkages are crucial for M\&A knowledge transfer: Complementary employee skills are likely to be particularly valuable and are more likely to be transferred between the merging firms, trust and collective teaching represent important sociocultural mechanisms for transferring tacit and socially complex knowledge, whereas cultural integration creates a shared social platform for knowledge transfer. This proposition advances the M\&A literature by clarifying the role of these underresearched sociocultural interfirm linkages as mechanisms through which knowledge transfer takes place in M\&As. 
Next, we discussed how HR flexibility influences these sociocultural interfirm linkages. Consistent with Wright and Snell (1998) and Way et al. (2015), we viewed HR as consisting of three components: namely, employee skills, employee behavior, and HR practices. Furthermore, flexibility in these three HR components was described as consisting of the dimensions of resource and coordination flexibility. We proposed that resource and coordination flexibility in employee skills are vital for providing a basis for complementary employee skills in M\&As because a broader employee skill base (resource flexibility in employee skills) that can easily be deployed between the acquiring and target firms (coordination flexibility in employee skills) allows the partners to pursue goals that they could not have achieved on their own (complementarity in employee skills). Furthermore, we argued that resource and coordination flexibility in employee behavior facilitate the creation of relation-specific assets (trust), knowledge-sharing routines (collective teaching), and effective governance (cultural integration) in M\&As because they increase the willingness of employees to participate in the development of these interfirm linkages. We also proposed that resource and coordination flexibility in the HR practices of the merging firms facilitates the alignment of the HR practices of the acquiring and target firms, which helps create a feeling of equality and togetherness. This supports the creation of sociocultural interfirm linkages (trust, collective teaching, and cultural integration). We contribute to the M\&A literature by extending the conceptualizations of HR in M\&As and by elaborating on the value creation mechanisms of HR in M\&As.

Finally, we extended previous discussions concerning the effect of cultural differences on M\&A outcomes (Teerikangas \& Very, 2006) by suggesting that the role of organizational cultural differences in M\&As can be understood through their influence on HR flexibility. Previous M\&A studies have found mixed effects concerning the relationship between organizational cultural differences and acquisition outcomes (Stahl \& Voigt, 2008; Vaara et al., 2012; Weber et al., 1996). Based on our model, the positive influence of organizational cultural differences described in previous studies can be explained by increased resource flexibility in employee skills: Organizational cultural differences provide a broader skill base for the employees in the combined firm. In contrast, the negative influence of organizational cultural differences reported in prior research can be ascribed to the fact that broad employee skill bases are more difficult to understand and to manage, which decreases coordination flexibility in employee skills. The negative effect of organizational cultural differences can also be related to decreased flexibility in employee behavior due to negative social identification (Vaara, 2003), and decreased flexibility in HR practices that stem from sharply different organizational cultural contexts (Chatterjee et al., 1992; Datta, 1991; Evans et al., 2011; Weber et al., 1996). Thus, by integrating the concept of HR flexibility, our model is able to distinguish further mechanisms by which cultural differences affect M\&A outcomes. This has been called for in earlier studies in order to interpret the mixed results reported in prior M\&A research (Teerikangas \& Very, 2006) and to open the black box of M\&A integration (Stahl \& Voigt, 2008).

Our model offers several avenues for further research. First, it would be appropriate to test our model empirically. To date, there are still relatively few empirical studies on HR flexibility, and none in the M\&A context. The studies of Bhattacharya et al. (2005) and Way et al. (2015) offer two alternative empirical measurements that can be modified to fit the M\&A context. The Way et al. (2015) instrument explicitly distinguishes between resource and coordination flexibility 
dimensions, in a way that is similar to how we outlined HR flexibility in our model. Second, the relationship between organizational cultural differences and employee behavior may be more complex than illustrated in our model. We excluded some possible relationships in order to keep the model focused on sociocultural factors. For instance, the effect of organizational cultural differences may be further moderated by factors related to industry (e.g., service vs. manufacturing) (Pablo, 1994), the partner firms (e.g., prior performance of the companies) (Haunschild, Moreland, \& Murrell, 1994), or the deal (e.g., friendly vs. hostile M\&As) (Hitt, Harrison, Ireland, \& Best, 1998). We recommend that future empirical studies test for these kinds of moderating effects, or at least control for the effect of such variables. Finally, future research can extend the concept of HR flexibility to include "external" aspects. In our model, we focused on "internal" HR flexibility (Martinez-Sanchez, Vela-Jimenez, Perez-Perez, \& de-LuisCarnicer, 2009): the internal labor market and work organization within the combined firm. In other words, we primarily considered the flexibility of the current employees of the acquiring and target firms, specifically how employees can be assigned to new work roles within the combined firm. We did not consider that "internal" flexibility may increase "external" flexibility in the sense that employees with a high level of resource flexibility in skills and behavior may be more mobile across competing firms, and may therefore be more prone to leave the firm if they disagree with the integration process. ${ }^{2}$ This highlights the importance of ensuring that employee salaries and working conditions are competitive within the industry.

Our model has important managerial implications. We emphasize the importance of facilitating knowledge transfer between the merging firms by creating sociocultural interfirm linkages: complementary employee skills, trust, collective teaching, and cultural integration. We further maintain that these linkages can be facilitated by HR flexibility. Thus, merging firms should develop HR flexibility internally. For example, they can invest in developing a broad employee skill base using a job rotation program, and create incentives that support flexible employee behavior in the firm. Furthermore, the merging firms can try to design HR practices that are broad enough to be applied across the firms or easily adjustable if new needs arise. Moreover, merging firms should analyze the level of HR flexibility and employee skill complementarity in the partner firm. For instance, acquirers can try to identify where potential complementarities are located in the target firm, and create incentives to retain employees with complementary skills. "Human due diligence" can also help the acquirer evaluate the attitudes of target firm members (Harding \& Rouse, 2007) that are likely to affect the degree of flexibility in the behavior of target firm employees. These measures can help the merging firms anticipate and reduce problems in the development of interfirm linkages. Finally, it is important that the managers of the merging firms understand the multifaceted effects of organizational cultural differences on HR flexibility. We propose that organizational cultural differences may contribute to broader employee skills, yet we warn that these kinds of skill sets may be more difficult to coordinate. Owing to negative social identification, organizational cultural differences may also decrease behavioral flexibility of employees and can make it more difficult to align HR practices across the acquiring and the target firms. A cultural audit can help the firms anticipate the effect of organizational cultural differences and adjust the integration process accordingly.

We hope that our study furthers a more comprehensive understanding of the multifaceted role of sociocultural factors in M\&As, and that it will inspire further theoretical and empirical studies on sociocultural aspects in this context. 


\section{Acknowledgements}

This article was accepted under the editorship of Deborah E. Rupp. The authors would like to thank the Associate Editor Annette Ranft and two anonymous reviewers for their excellent comments and guidance in improving the article.

\section{Notes}

1. Although the degree of organizational change differs across various types of mergers and acquisitions (M\&As), M\&As increasingly involve horizontal deals in which a great degree of integration is essential for value creation (Gaughan, 2007; Seo \& Hill, 2005).

2. We want to thank one of the anonymous reviewers for pointing this out.

\section{References}

Aguilera, R. V., Dencker, J. H. 2004. The role of human resource management in cross-border mergers and acquisitions. International Journal of Human Resource Management, 15: 13551370 .

Ahammad, M. F., Glaister, K. W. 2011. Postacquisition management and performance of crossborder acquisitions. International Studies of Management and Organization, 41: 59-75.

Austin, J. E., Leonard, H. B. 2008. Can the virtuous mouse and the wealthy elephant live happily ever after? California Management Review, 51: 77-102.

Barney, J. B. 1986. Organizational culture: Can it be a source of sustained competitive advantage? Academy of Management Review, 11: 656-665.

Barney, J. 1991. Firm resources and sustained competitive advantage. Journal of Management, 17: 99-120.

Beltran-Martin, I., Roca-Puig, V., Escrig-Tena, A., Bou-Llusar, J. C. 2008. Human resource flexibility as a mediating variable between high performance work systems and performance. Journal of Management, 34: 1009-1044.

Bhattacharya, M., Gibson, D. E., Doty, D. H. 2005. The effects of flexibility in employee skills, employee behaviors, and human resource practices on firm performance. Journal of Management, 31: 622-640.

Birkinshaw, J., Bresman, H., Håkanson, L. 2000. Managing the post-acquisition integration process: How the human integration and task integration processes interact to foster value creation. Journal of Management Studies, 37: 395-425. 
Björkman, I., Søderberg, A.-M. 2003. Quo vadis, HR? An analysis of the roles played by the HR function during the post-merger process. In Søderberg, A.-M., Vaara, E. (Eds.), Merging across borders: 203-228. Copenhagen, Denmark: Copenhagen Business School Press.

Björkman, I., Stahl, G. K., Vaara, E. 2007. Cultural differences and capability transfer in crossborder acquisitions: The mediating roles of capability complementarity, absorptive capacity, and social integration. Journal of International Business Studies, 38: 658-672.

Bowen, D. E., Ostroff, C. 2004. Understanding HRM-firm performance linkages: The role of the "strength" of the HRM system. Academy of Management Review, 29: 203-221.

Bresman, H., Birkinshaw, J., Nobel, R. 1999. Knowledge transfer in international acquisitions. Journal of International Business Studies, 30: 439-462.

Capron, L. 1999. The long-term performance of horizontal acquisitions. Strategic Management Journal, 20: 987-1018.

Capron, L., Pistre, N. 2002. When do acquirers earn abnormal returns? Strategic Management Journal, 23: 781-794.

Cartwright, S., Cooper, C. L. 1993. The role of culture compatibility in successful organizational marriage. Academy of Management Executive, 7: 57-70.

Cartwright, S., Cooper, C. L. 1996. Managing mergers, acquisitions, and strategic alliances. Oxford, UK: Butterworth \& Heinemann.

Cartwright, S., Schoenberg, R. 2006. Thirty years of mergers and acquisitions research: Recent advances and future opportunities. British Journal of Management, 17: S1-S5.

Chatterjee, S., Lubatkin, M. H., Schweiger, D. M., Weber, Y. 1992. Cultural differences and shareholder value in related mergers: Linking equity and human capital. Strategic Management Journal, 13: 319-334.

Chaudhuri, S. 2005. Managing human resources to capture capabilities: Case studies in high technology acquisitions. In Stahl, G. K., Mendenhall, M. E. (Eds.), Mergers and acquisitions: Managing culture and human resources: 277-301. Stanford, CA: Stanford University Press.

Chaudhuri, S., Tabrizi, B. 1999. Capturing the real value in high-tech acquisitions. Harvard Business Review, 77: 123-130.

Chua, C. H., Engeli, H.-P., Stahl, G. 2005. Creating a new identity and high-performance culture at Novartis: The role of leadership and human resource management. In Stahl, G. K., Mendenhall, M. E. (Eds.), Mergers and acquisitions: Managing culture and human resources: 379-398. Stanford, CA: Stanford University Press. 
Datta, D. 1991. Organizational fit and acquisition performance: Effects of post-acquisition integration. Strategic Management Journal, 12: 281-297.

Davenport, T. H., Prusak, L. 1998. Working knowledge: How organizations manage what they know. Boston: Harvard Business School Press.

Dyer, J. H., Singh, H. 1998. The relational view: Cooperative strategy and sources of interorganizational competitive advantage. Academy of Management Review, 23: 660-679.

Elsass, P. M., Veiga, J. F. 1994. Acculturation in acquired organizations: A force field perspective. Human Relations, 47: 431-453.

Empson, L. 2001. Fear of exploitation and fear of contamination: Impediments to knowledge transfer in mergers between professional service firms. Human Relations, 54: 839-863.

Evans, P., Pucik, V. 2005. People and cultural aspects of mergers and acquisitions: What are the lessons ... . and the challenges? In Stahl, G. K., Mendenhall, M. E. (Eds.), Mergers and acquisitions: Managing culture and human resources: 412-422. Stanford, CA: Stanford University Press.

Evans, V., Pucik, V., Björkman, I. 2011. The global challenge: International human resource management. Boston: McGraw-Hill.

Frantz, T. L. 2012. A social network view of post-merger integration. Advances in Mergers and Acquisitions, 10: 161-176.

Gates, S., Very, P. 2003. Measuring performance during M\&A integration. Long Range Planning, 36: 167-185.

Gaughan, P. A. 2007. Mergers, acquisitions, and corporate restructurings. Hoboken, NJ: John Wiley.

Graebner, M. E. 2004. Momentum and serendipity: How acquired leaders create value in the integration of technology firms. Strategic Management Journal, 25: 751-777.

Graebner, M. E. 2009. Caveat venditor: Trust asymmetries in acquisitions of entrepreneurial firms. Academy of Management Journal, 52: 435-472.

Haleblian, J., Devers, C. E., McNamara, G., Carpenter, M. E., Davison, R. B. 2009. Taking stock of what we know about mergers and acquisitions: A review and research agenda. Journal of Management, 35: 469-502.

Harding, D., Rouse, T. 2007. Human due diligence. Harvard Business Review, 85: 124-131.

Haspeslagh, P., Jemison, D. B. 1991. Managing acquisitions: Creating value through corporate renewal. New York: Free Press. 
Haunschild, P. R., Moreland, R. L., Murrell, A. J. 1994. Sources of resistance to mergers between groups. Journal of Applied Social Psychology, 24: 1150-1178.

Hitt, M., Harrison, J., Ireland, R. D., Best, A. 1998. Attributes of successful and unsuccessful acquisitions of US firms. British Journal of Management, 9: 91-114.

Hunt, W., Downing, S. 1990. Mergers, acquisitions and human resource management. International Journal of Human Resource Management, 1: 195-210.

Ivancevich, J. M., Schweiger, D. M., Power, F. R. 1987. Strategies for managing human resources during mergers and acquisitions. Human Resource Planning, 10: 19-35.

Jap, S. D. 1999. Pie-expansion efforts: Collaboration processes in buyer-supplier relationships. Journal of Marketing Research, 36: 461-475.

Junni, P. 2011. Knowledge transfer in acquisitions: Fear of exploitation and contamination. Scandinavian Journal of Management, 27: 307-321.

Junni, P., Sarala, R. M. 2011. Causal ambiguity, partner attractiveness, and cultural integration as determinants of knowledge transfer: Evidence from Finnish acquisitions. European Journal of International Management, 5: 346-372.

Kavanagh, M. H., Ashkanasy, N. M. 2006. The impact of leadership and change management strategy on organizational culture and individual acceptance of change during a merger. British Journal of Management, 17: S81-S103.

King, D. R., Dalton, D. R., Daily, C. M., Covin, J. G. 2004. Metaanalyses of post-acquisition performance: Indications of unidentified moderators. Strategic Management Journal, 25: 187200.

Krishnan, H. A., Miller, A., Judge, W. O. 1997. Diversification and top management team complementarity: Is performance improved by merging similar or dissimilar teams? Strategic Management Journal, 18: 361-374.

Kühlmann, T., Dowling, P. J. 2005. DaimlerChrysler: A case study of a cross-border merger. In Stahl, G. K., Mendenhall, M. E. (Eds.), Mergers and acquisitions: Managing culture and human resources: 323-350. Stanford, CA: Stanford University Press.

Lakshman, C. 2011. Postacquisition cultural integration in mergers and acquisitions: A knowledge-based approach. Human Resource Management, 50: 605-623.

Lubatkin, M., Schweiger, D., Weber, Y. 1999. Top management turnover in related M\&As: An additional test of the theory of relative standing. Journal of Management, 25: 55-74. 
Marks, M. L., Mirvis, P. H. 2011. A framework for the human resources role in managing culture in mergers and acquisitions. Human Resource Management, 50: 859-877.

Marmenout, K. 2011. Peer interaction in mergers: Evidence of collective rumination. Human Resource Management, 50: 783-808.

Martinez-Sanchez, A., Vela-Jimenez, J., Perez-Perez, M., de-Luis-Carnicer, P. 2009. Interorganizational cooperation and environmental change: Moderating effects between flexibility and innovation performance. British Journal of Management, 20: 537-561.

Milliman, J., von Glinow, M. A., Nathan, M. 1991. Organizational life cycles and strategic international human resource management in multinational companies: Implications for congruence theory. Academy of Management Review, 16: 318-339.

Napier, N. K. 1989. Mergers and acquisitions, human resource issues and outcomes: A review and suggested typology. Journal of Management Studies, 3: 271-289.

O’Reilly, C. A., Chatman, J. A. 1996. Culture as social control: Corporations, cults, and commitment. Research in Organizational Behavior, 18: 157-200.

Pablo, A. L. 1994. Determinants of acquisition integration level: A decision-making perspective. Academy of Management Journal, 37: 803-836.

Parkhe, A. 1993. Strategic alliance structuring: A game theoretic and transaction cost examination of interfirm cooperation. Academy of Management Journal, 36: 794-829.

Ranft, A. 2006. Knowledge preservation and transfer during post-acquisition integration. Advances in Mergers and Acquisitions, 5: 51-67.

Ranft, A. L., Lord, M. D. 2002. Acquiring new technologies and capabilities: A grounded model of acquisition implementation. Organization Science, 13: 420-441.

Rees, C., Edwards, T. 2009. Management strategy and HR in international mergers: Choice, constraint and pragmatism. Human Resource Management Journal, 19: 24-39.

Risberg, A. 2001. Employee experiences of acquisition processes. Journal of World Business, 36: $58-84$.

Rousseau, D. M., Sitkin, S. B., Burt, R. S., Camerer, C. 1998. Not so different after all: A crossdiscipline view of trust. Academy of Management Review, 23: 393-404.

Sarala, R., Vaara, E. 2010. Cultural differences, convergence, and crossvergence as explanations of knowledge transfer in international acquisitions. Journal of International Business Studies, 41: 1365-1390. 
Schein, E. 1996. Culture: The missing concept in organization studies. Administrative Science Quarterly, 41: 229-240.

Schuler, R. S., Jackson, S. E. 2001. HR issues and activities in mergers and acquisitions. European Management Journal, 19: 59-75.

Schweiger, D. M., Goulet, P. K. 2005. Facilitating acquisition integration through deep-level cultural learning interventions: A longitudinal field experiment. Organization Studies, 26: 14771499.

Schweiger, D. M., Lippert, R. L. 2005. Integration: The critical link in M\&A value creation. In Stahl, G. K., Mendenhall, M. E. (Eds.), Mergers and acquisitions: Managing culture and human resources: 17-45. Stanford, CA: Stanford University Press.

Schweizer, L. 2005. Organizational integration of acquired biotechnology companies into pharmaceutical companies: The need for a hybrid approach. Academy of Management Journal, 48: 1051-1074.

Seo, M., Hill, N. S. 2005. Understanding the human side of merger and acquisition: An integrative framework. Journal of Applied Behavioral Science, 41: 422-443.

Shreyögg, G. 2005. The role of corporate cultural diversity in integrating merger and acquisitions. In Stahl, G. K., Mendenhall, M. E. (Eds.), Mergers and acquisitions: Managing culture and human resources: 108-125. Stanford, CA: Stanford University Press.

Shrivastava, P. 1986. Postmerger integration. Journal of Business Strategy, 7: 65-76.

Stahl, G. K., Angwin, D. N., Very, P., Gomes, E., Weber, Y., Tarba, S. Y., Noorderhaven, N., Benyamini, H., Bouckenooghe, D., Chreim, S., Durand, M., Hassett, M. E., Kokk, G., Mendenhall, M. E., Mirc, N., Miska, C., Park, K. M., Reynolds, N.-S., Rouzies, A., Sarala, R. M., Soloti, S. L., Søndergaard, M., Yildiz, H. E. 2013. Sociocultural integration in mergers and acquisitions: Unresolved paradoxes and directions for future research. Thunderbird International Business Review, 55: 333-356.

Stahl, G. K., Larsson, R., Kremershof, I., Sitkin, S. B. 2011. Trust dynamics in acquisitions: A case survey. Human Resource Management, 50: 575-603.

Stahl, G. K., Maznevski, M. L., Voigt, A., Jonsen, K. 2010. Unraveling the effects of cultural diversity in teams: A meta-analysis of research on multicultural work group. Journal of International Business Studies, 41: 690-709.

Stahl, G. K., Mendenhall, M. E., Weber, Y. 2005. Research on socio-cultural integration in mergers and acquisitions: Points of agreement, paradoxes, and avenues for future research. In Stahl, G. K., Mendenhall, M. E. (Eds.), Mergers and acquisitions: Managing culture and human resources: 401-411. Stanford, CA: Stanford University Press. 
Stahl, G. K., Sitkin, S. B. 2005. Trust in mergers and acquisitions. In Stahl, G. K., Mendenhall, M. E. (Eds.), Mergers and acquisitions: Managing culture and human resources: 82-102.

Stanford, CA: Stanford Business Press.

Stahl, G. K., Voigt, A. 2008. Do cultural differences matter in mergers and acquisitions? A tentative model for examination. Organization Science, 19: 160-176.

Teerikangas, S., Very, P. 2006. The culture-performance relationship in M\&A: From yes/no to how. British Journal of Management, 17: S31-S48.

Teerikangas, S., Very, P., Pisano, V. 2011. Integration managers' value-capturing roles and acquisition performance. Human Resource Management, 50: 651-683.

Vaara, E. 2003. Post-acquisition integration as sensemaking: Glimpses of ambiguity, confusion, hypocrisy, and politicization. Journal of Management Studies, 40: 859-894.

Vaara, E., Sarala, R., Stahl, G., Björkman, I. 2012. The impact of national and organizational cultural differences on post-acquisition integration outcomes. Journal of Management Studies, 49: 1-27.

Vaara, E., Tienari, J., Björkman, I. 2003. Knowledge transfer around "best practices": A sensemaking perspective. Nordic Organization Studies, 5: 37-57.

Vaara, E., Tienari, J., Irrmann, O. 2007. Crafting and international identity: The Nordea case. In Lerpold, L., Ravasi, D., van Rekom, J., Soenen, G. (Eds.), Organizational identity in practice: 215-231. London: Routledge.

van Dick, R., Ullrich, J., Tissington, P. A. 2006. Working under a black cloud: How to sustain organizational identification after a merger. British Journal of Management, 17: S69-S79.

Vermeulen, F. 2005. How acquisitions can revitalize companies. Sloan Management Review, 46: 44-51.

Vermeulen, F., Barkema, H. G. 2001. Learning through acquisitions. Academy of Management Journal, 44: 457-476.

Way, S. A., Tracey, J. B., Fay, C. H., Wright, P. M., Snell, S. A., Chang, S., Gong, Y. 2015. Validation of a multidimensional HR flexibility measure. Journal of Management, 41: 10981131.

Weber, Y. 1996. Corporate cultural fit and performance in mergers and acquisitions. Human Relations, 49: 1181-1202.

Weber, Y. 2012. Introduction. In Weber, Y. (Ed.), Handbook of research on mergers and acquisitions: ix-xix. Cheltenham, UK: Edward Elgar. 
Weber, Y., Drori, I. 2011. Integrating organizational and human behavior perspectives on mergers and acquisitions: Looking inside the black box. International Studies of Management and Organization, 41: 88-112.

Weber, Y., Fried, Y. 2011. The dynamic of employees' reactions during post merger integration process. Human Resource Management, 50: 777-781.

Weber, Y., Shenkar, O., Raveh, A. 1996. National and corporate cultural fit in mergers/acquisitions: An exploratory study. Management Science, 42: 1215-1227.

Weber, Y., Tarba, S. Y. 2012. Mergers and acquisitions process: The use of corporate culture analysis. Cross-Cultural Management, 19: 288-303.

Westphal, T., Shaw, V. 2005. Knowledge transfers in acquisitions-An exploratory study and model. Management International Review, 45: 75-100.

Wright, P. M., Snell, S. A. 1998. Toward a unifying framework for exploring fit and flexibility in strategic human resource management. Academy of Management Review, 23: 756-772.

Zafar, N., Chang, V. 2012. Berkley-Haas case series_-SpeedSim made to exit! California Management Review, 54: 143-155.

Zander, U., Zander, L. 2010. Opening the grey box: Social communities, culture and knowledge in acquisitions. Journal of International Business Studies, 41: 27-37.

Zhao, Z. J., Anand, J. 2009. A multilevel perspective on knowledge transfer: Evidence from the Chinese automotive industry. Strategic Management Journal, 30: 959-983.

Zhao, Z. J., Anand, J. 2013. Beyond boundary spanners: The "collective bridge" as an efficient interunit structure for transferring collective knowledge. Strategic Management Journal, 34: 1513-1530. 